\title{
Scalp Nerve Block Using Lidocaine or Levobupivacaine Both Provide Good Hemodynamic Control during the Cranial Fixation of Cervical Spine Surgery
}

\author{
Cheng, Hsiao-Liang M.D. ( b87401032@ntu.edu.tw ) \\ 1. Department of Anesthesiology, National Taiwan University Hospital and National Taiwan University Medical College, Taipei, Taiwan \\ 2. Graduate Institute of Biomedical Electronics and Bioinformatics, College of Electrical Engineering and Computer Science, National \\ Taiwan University, Taipei, Taiwan
}

\section{Background:}

Regional scalp nerve block is an old but very useful technique in brain surgery. It includes the local anesthetics injection to supratrochlear and supraorbital nerves, zygomaticotemporal nerve, auriculotemporal nerve, and lesser occipital, greater occipital nerves. Combined with general anesthesia, it provides good blood pressure control, as well as satisfying pain management.

During many brain surgeries, the cranial fixation causes the most significant hemodynamic change, even more severe than incision to the scalp, thus intravenous analgesics or antihypertensive agents are required. If scalp nerve block is applied, the hemodynamics will be more stable.

If a cervical spine surgery is performed from posterior neck, it usually require cranial fixation as well. Although scalp nerve block does not provide the analgesic benefit of surgical incision site like brain surgery, we suppose it could help the hemodynamic control of cervical spine surgery.

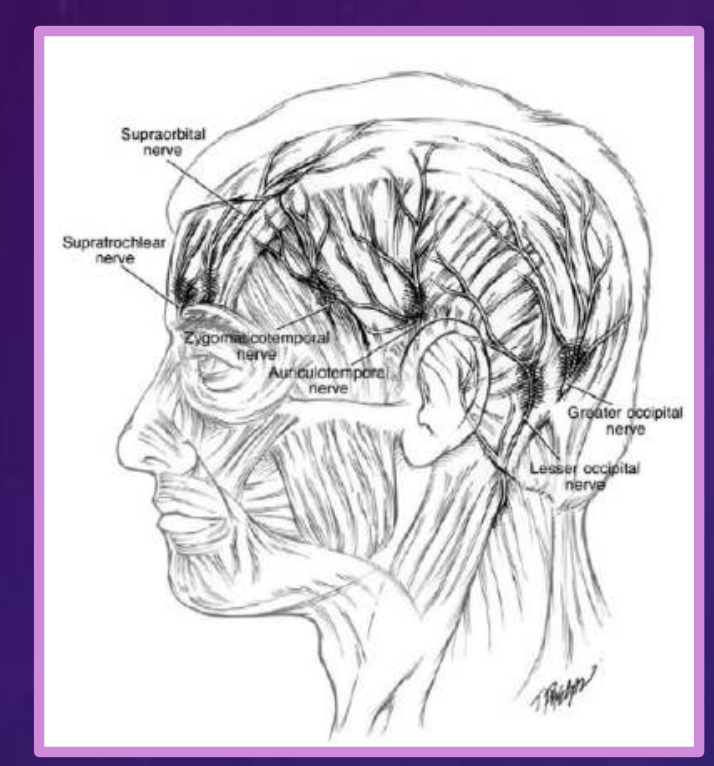

\section{Materials and Methods:}

Our study includes patients underwent cervical spine surgery from 2015/05 to 2016/04 and the exclusion criteria are emergent surgery, patients younger than 18 years old or elder and 100 years old, or any contraindication of nerve block such as local infection or allergy. The anesthesia induction agents were fentanyl (2-3 $\mathrm{mcg} / \mathrm{Kg})$, propofol $(2-3 \mathrm{mg} / \mathrm{Kg}$ ) or thiamylal $(4-6$ $\mathrm{mg} / \mathrm{Kg})$ and cisatracurium $(0.15-0.2 \mathrm{mg} / \mathrm{Kg})$ or rocuronium $(0.8-$ $1.0 \mathrm{mg} / \mathrm{Kg})$, followed by sevoflurane (0.7-1.3 MAC) or desflurane (0.7-1.3 MAC) or propofol ( $\mathrm{TCl}$ Ce $3.5-5.5 \mathrm{mcg} / \mathrm{ml}$ ) for maintainance. If regional scalp nerve block was performed, the local anesthetics were $0.5 \%$ levobupivacaine or $2 \%$ lidocaine, and we injected about $3 \mathrm{ml}$ each site for auriculotemporal and lesser occipital nerve after general anesthesia induction. Since the head and neck positioning for greater occipital nerve block may possibly cause cervical nerve damage in these patients, we did not perform it. In all patients, no matter scalp nerve block was performed or not, we closely monitored and recorded the heart rate and blood pressure during cranial fixation, if there is significant hemodynamic change, we would increase anesthesia depth and/ or add fentanyl or antihypertensive drugs such as nitroglycerin, nicardipine, or labetalol.

\begin{tabular}{|l|l|l|}
\hline Group & Control & Scalp nerve block \\
\hline Number & 77 & 17 \\
\hline Baseline HR & 79.0 & 79.6 \\
\hline HR after cranial fixation & 92.0 & 87.6 \\
\hline HR change & $+16.5 \%$ & $+10.1 \%$ \\
\hline Baseline SBP & 146.8 & 146.1 \\
\hline SBP after cranial fixation & 138.4 & 121.8 \\
\hline SBP change & $-5.7 \%$ & $-16.6 \%$ \\
\hline Baseline DBP & 81.8 & 83.8 \\
\hline DBP after cranial fixation & 86.1 & 73.9 \\
\hline DBP change* & $+5.3 \%$ & $-7.2 \%$ \\
\hline
\end{tabular}
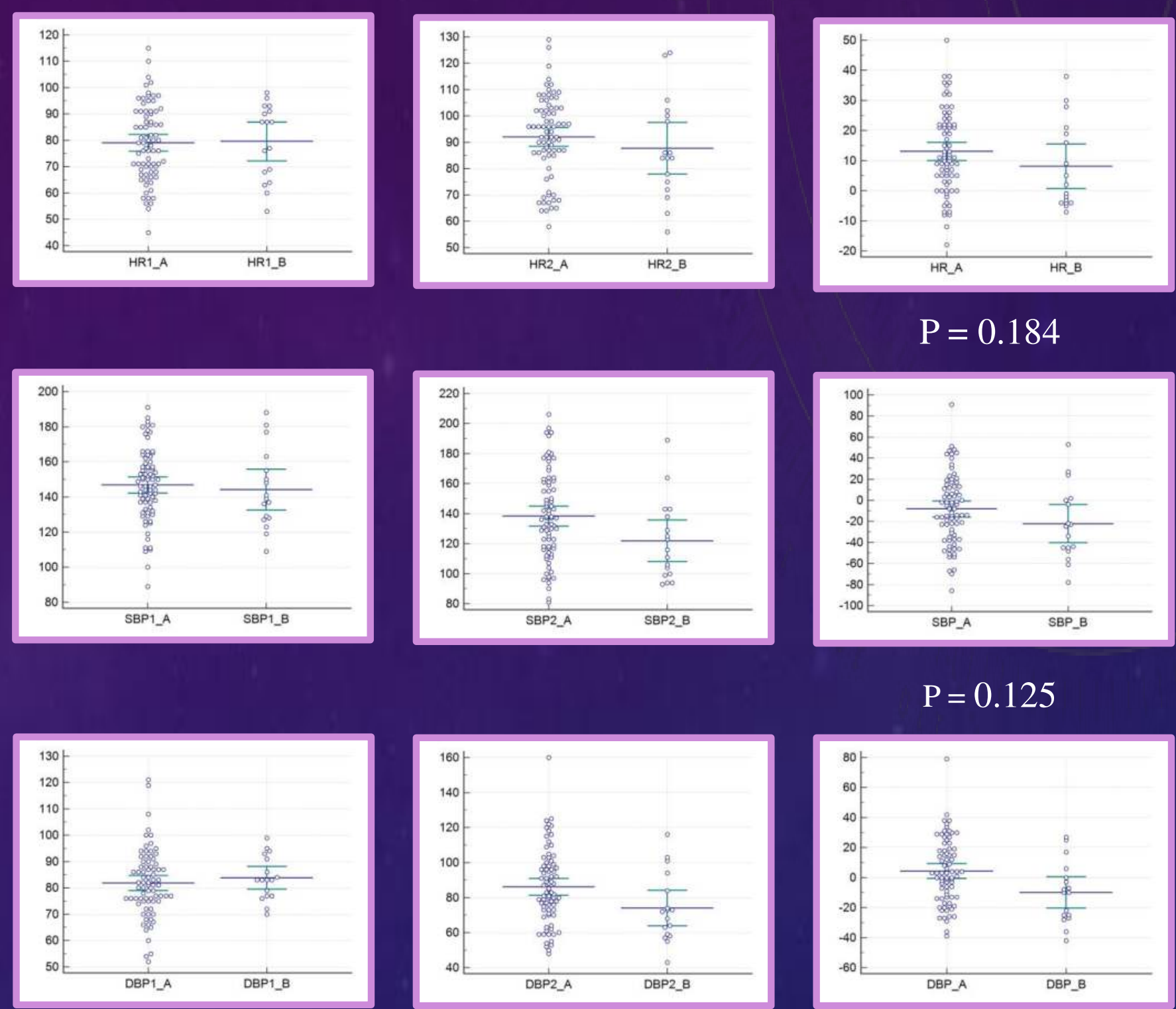

Results:

$\mathrm{P}=0.016$

The total number of elective adult cervical spine surgeries during these six months were 214 , and 94 of these patients required cranial fixation. All of them were in prone position with their head fixed using Mayfield skull clamp. Seventeen patient received regional scalp nerve block and 77 didn't. The baseline heart rate (HR), systolic blood pressure (SBP), diastolic blood pressure (DBP) were 79.0 beats/min vs 79.6 beats $/ \mathrm{min}, 146.8$ $\mathrm{mmHg}$ vs $146.1 \mathrm{mmHg}, 81.8 \mathrm{mmHg}$ vs $83.8 \mathrm{mmHg}$ in control and scalp nerve block groups. After cranial fixation, the HR, SBP, DBP were 92.0 beats $/ \mathrm{min}(+16.5 \%)$ vs 87.6 beats $/ \mathrm{min}(+10.1 \%)$, $138.4 \mathrm{mmHg}(-5.7 \%)$ vs $121.8 \mathrm{mmHg}(-16.6 \%), 86.1 \mathrm{mmHg}$ $(+5.3 \%)$ vs $73.9 \mathrm{mmHg}(-7.2 \%)$ in control and scalp nerve block groups. The DBP change value and percentage were significantly different ( $p$-value 0.016 and 0.014 ). The HR, SBP, DBP difference were not significant between lidocaine and levobupivacine subgroups. There was no adverse event caused by regional scalp nerve block in our study.

\section{Conclusion:}

In patients with regional scalp nerve block to auriculotemporal and lesser occipital nerve, the hemodynamic control, especially diastolic blood pressure, is better than patients without regional scalp nerve block. It is an effective and safe technique for posterior cervical spine surgery requiring cranial fixation.

1. Regional scalp block for postcraniotomy analgesia: a systematic review and meta-analysis Guilfoyle MR, Helmy A, Duane D, Hutchinson PJ. Anesth Analg. 2013 May;116(5):1093-102.

2. 2. A review of scalp blockade for cranial surgery. Papangelou A, Radzik BR, Smith T, Gottschalk A. J Clin Anesth. 2013 Mar;25(2):150-9.

3. Effect of scalp blocks with levobupivacaine on recovery profiles after craniotomy for aneurysm clipping: a randomized, double-blind, and controlled study. Hwang JY, Bang JS, Oh CW, Joo JD, Park SJ, Do SH, Yoo YJ, Ryu JH. World Neurosurg. 2015 Jan;83(1):108-13.

4. The effect of scalp block and local infiltration on the haemodynamic and stress response to skull-pin placement for craniotomy. Geze S, Yilmaz AA, Tuzuner F. Eur J Anaesthesiol. 2009 Apr;26(4):298-303. 